\title{
Introduction of the phzH Gene of Pseudomonas chlororaphis PCL1391 Extends the Range of Biocontrol Ability of Phenazine-1-Carboxylic Acid-Producing Pseudomonas spp. Strains
}

\author{
Thomas F. C. Chin-A-Woeng, ${ }^{1}$ Jane E. Thomas-Oates, ${ }^{2}$ Ben J. J. Lugtenberg, ${ }^{1}$ \\ and Guido V. Bloemberg' \\ ${ }^{1}$ Leiden University, Institute of Molecular Plant Sciences, Clusius Laboratory, Wassenaarseweg 64, $2333 \mathrm{AL}$ \\ Leiden, The Netherlands; and ${ }^{2}$ Michael Barber Centre for Mass Spectrometry, Department of Chemistry, \\ University of Science and Technology in Manchester (UMIST), P.O. Box 88, Manchester, M60 1QD, U.K. \\ Submitted 1 February 2001; Accepted 17 April 2001.
}

\begin{abstract}
Pseudomonas chlororaphis PCL1391 controls tomato foot and root rot caused by Fusarium oxysporum f. sp. radicislycopersici. Its biocontrol activity is mediated by the production of phenazine-1-carboxamide (PCN). In contrast, the take-all biocontrol strains $P$. fluorescens $2-79$ and $P$. aureofaciens 30-84, which produce phenazine-1-carboxylic acid (PCA), do not control this disease. To determine the role of the amide group in biocontrol, the PCN biosynthetic genes of strain PCL1391 were identified and characterized. Downstream of $p h z A$ through $p h z G$, the novel phenazine biosynthetic gene $p h z H$ was identified and shown to be required for the presence of the 1-carboxamide group of PCN because a phzH mutant of strain PCL1391 accumulated PCA. The deduced PhzH protein shows homology with asparagine synthetases that belong to the class II glutamine amidotransferases, indicating that the conversion of PCA to PCN occurs via a transamidase reaction catalyzed by PhzH. Mutation of $\mathrm{phzH}_{\mathrm{H}}$ caused loss of biocontrol activity, showing that the 1-carboxamide group of $\mathrm{PCN}$ is crucial for control of tomato foot and root rot. PCN production and biocontrol activity of the mutant were restored by complementing the $\mathrm{phzH}$ gene in trans. Moreover, transfer of $\mathrm{phzH}$ under control of the tac promoter to the PCA-producing biocontrol strains $\boldsymbol{P}$. fluorescens 2-79 and $\boldsymbol{P}$. aureofaciens 30-84 enabled these strains to produce PCN instead of PCA and suppress tomato foot and root rot. Thus, we have shown, for what we believe is the first time, that the introduction of a single gene can efficiently extend the range of the biocontrol ability of bacterial strains.
\end{abstract}

Additional keywords: antibiotic, antifungal metabolite, biopesticide, microbiological control, phytopathogenic fungi.

The biological control of plant pests by application of biological control agents holds great promise as a safer and envi-

Corresponding author: T. F. C. Chin-A-Woeng;

Telephone: +31 71 5275072; Fax: +31 71 5275088;

E-mail: chin@ rulbim.leidenuniv.nl ronmentally friendlier alternative to the use of chemical pesticides or as an addition to them. Pseudomonads are able to exhibit inhibitory activity toward phytopathogens and have been shown to be important candidates for application as biocontrol agents (Weller and Cook 1983). A common mechanism underlying this antagonistic activity is the production of antifungal compounds produced by these biocontrol agents, which include the secretion of phenazine-1-carboxylic acid (PCA) (Thomashow and Weller 1988), 2,4-diacetylphloroglucinol (Keel et al. 1992), pyrrolnitrin (Howell and Stipanovic 1979), hydrogen cyanide (Voisard et al. 1989), siderophores (Becker and Cook 1988), and hydrolytic enzymes such as chitinases (Shapira et al. 1989), proteases (Dunlap et al. 1997; Dunne et al. 1998), cellulase (Chatterjee et al. 1995), and $\beta$ glucanases (Jijakli and Lepoivre 1998; RuizDuenas and Martinez 1996). In addition, Pseudomonas spp. bacteria can efficiently exploit plant root exudate compounds as nutrient sources (Lugtenberg et al. 1999); are abundantly present on many plant root systems, which is indicative of their adaptive potential (Sands and Rovira 1971); and have a high growth rate relative to many other soil bacteria.

There is much interest in the development of new biocontrol agents to improve the performance and extend the range of controlled crops and target pathogens. Strategies include the combination of biocontrol strains in a consortium, with the objective of improving upon the level of protection achieved when each strain is used singly (De Boer et al. 1999; Dunne et al. 1998), or with a generation of genetically modified versions of the strain with increased or newly introduced metabolite production (Di Pietro et al. 1993; Duffy et al. 1996; Dunne et al. 1998; Lorito et al. 1994).

The tomato rhizosphere isolate Pseudomonas chlororaphis PCL1391 exhibits biocontrol activity against Fusarium oxysporum (Schlechtend.:Fr.) f. sp. radicis-lycopersici (W.R. Jarvis \& Shoemaker), the causal agent of tomato and radish foot and root rot. Strain PCL1391 produces phenazine-1carboxamide (PCN), also known as (oxo)chlororaphin, a phenazine derivative with antifungal activity against a number of important plant pathogens, including $F$. oxysporum f. sp. 
radicis-lycopersici, Rhizoctonia solani, Pythium ultimum, and Verticillium albo-atrum (Chin-A-Woeng et al. 1998). Phenazine and its derivatives are nitrogen-containing heterocyclic redox agents with broad-spectrum activity against gram-positive and gram-negative bacteria (Gerber 1984), fungi, and algae (Toohey et al. 1965), and these compounds are produced mainly by Pseudomonas and Streptomyces species (Ingram and Blackwood 1970). The production of PCN is limited to and characteristic for P. chlororaphis and some strains of $P$. aeruginosa (Turner and Messenger 1986). Although $P$. chlororaphis PCL1391 also produces a number of compounds such as chitinase, protease, and hydrogen cyanide (Chin-A-Woeng et al. 1998), which have been shown to be involved in the antifungal activity of other biocontrol strains (O'Sullivan et al. 1991; Shapira et al. 1989; Voisard et al. 1989), the production of PCN was shown to be the crucial metabolite for the biocontrol ability of strain PCL1391 in the tomato-F. oxysporum test system (Chin-AWoeng et al. 1998). Furthermore, P. aeruginosa PNA1 producing a mixture of PCA and PCN suppressed Fusarium wilt caused by $F$. oxysporum f. sp. ciceris and Pythium splendens (Anjaiah et al. 1998). Remarkably, two other biocontrol strains, P. fluorescens 2-79, which produces PCA, and $P$. aureofaciens 30-84, which produces a mixture of PCA and hydroxyphenazines that are able to suppress the take-all disease of wheat caused by Gaeumannomyces graminis var. tritici (Cook et al. 1995; Thomashow and Weller 1988; Thomashow et al. 1990), did not exhibit biocontrol activity

Table 1. Microorganisms and plasmids

\begin{tabular}{|c|c|c|}
\hline Strains-plasmids & Relevant characteristics & Reference or source \\
\hline \multicolumn{3}{|l|}{ Bacterial strains } \\
\hline PCL1391 & $\begin{array}{l}\text { Wild-type Pseudomonas chlororaphis producing phenazine-1-carboxamide isolated } \\
\text { from Spanish tomato rhizosphere with biocontrol ability of tomato foot and root } \\
\text { rot caused by Fusarium oxysporum f. sp. radicis-lycopersici }\end{array}$ & Chin-A-Woeng et al. 1998 \\
\hline $2-79$ & $\begin{array}{l}\text { Pseudomonas fluorescens strain whose biocontrol activity in a Gaeumannomyces } \\
\text { graminis var. tritici-wheat system is partly the result of phenazine-1-carboxylic } \\
\text { acid production }\end{array}$ & Thomashow and Weller 1988 \\
\hline PCL1113 & $\begin{array}{l}\text { PCL1391 derivative in which a promoterless Tn } 5 \operatorname{lux} A B \text { is inserted in the } p h z F \text { ho- } \\
\text { molog }\end{array}$ & Chin-A-Woeng et al. 1998 \\
\hline PCL1117 & $\begin{array}{l}\text { PCL1391 derivative in which a promoterless } \operatorname{Tn} 5 \operatorname{lux} A B \text { is inserted in the } p h z C \text { ho- } \\
\text { molog }\end{array}$ & Chin-A-Woeng et al. 1998 \\
\hline PCL1119 & $\begin{array}{l}\text { PCL1391 derivative in which a promoterless Tn } 5 \operatorname{lux} A B \text { is inserted in the } p h z B \text { ho- } \\
\text { molog }\end{array}$ & Chin-A-Woeng et al. 1998 \\
\hline PCL1120 & PCL1391 derivative in which a promoterless $\operatorname{Tn} 5 l u x A B$ is inserted in the $p h z H$ gene & This study \\
\hline PCL1121 & $\begin{array}{l}\text { PCL1391, derivative with a nonfunctional } p h z H \text { gene, mutated by homologous re- } \\
\text { combination }\end{array}$ & This study \\
\hline PCL1143 & PCL1120 harboring pMP6014 & This study \\
\hline PCL1145 & PCL1120 harboring pMP6012 & This study \\
\hline PCL1147 & P. fluorescens 2-79 harboring pMP6012 & This study \\
\hline PCL1149 & Pseudomonas aureofaciens 30-84 harboring pMP6012 & This study \\
\hline DH5 $\alpha$ & $\begin{array}{l}\text { supE44 } \Delta \text { lac } \mathrm{U} 169 \text { ( } \Phi 80 \text { lacZAM15) hsdR17 recA1 endA1 gyrA96 thi-1 relA1; gen- } \\
\text { eral-purpose Escherichia coli host strain used for the transformation and propaga- } \\
\text { tion of plasmids }\end{array}$ & Boyer and Roulland-Dussoix 1969 \\
\hline \multicolumn{3}{|l|}{ Fungi } \\
\hline ZUM2407 & F. oxysporum f. sp. radicis-lycopersici, causal agent of tomato foot and root rot & IPO-DLO, Wageningen, The Netherlands \\
\hline \multicolumn{3}{|l|}{ Plasmids } \\
\hline pIC20R & General-purpose cloning vector $\mathrm{Cb}^{\mathrm{R}}$ & Marsh et al. 1984 \\
\hline pBluescript & General-purpose cloning vector $\mathrm{Cb}^{\mathrm{R}}$ & Stratagene, La Jolla, CA, U.S.A. \\
\hline pRL1063a & Plasmid harboring promoterless $\mathrm{Tn} 5 \operatorname{lu} x A B$ transposon $\mathrm{Tc}^{\mathrm{R}}$ & Wolk et al. 1991 \\
\hline pMP5000 & $\begin{array}{l}\text { pIC20H with the tetracycline cassette from pWTT2081in the multicloning site } \mathrm{Tc}^{\mathrm{R}} \text {, } \\
\mathrm{Cb}^{\mathrm{R}}\end{array}$ & Van der Bij et al. 1996 \\
\hline pME6010 & Rhizosphere-stable cloning vector $\mathrm{pVS} 1$-based $\mathrm{Tc}^{\mathrm{R}}$ & Heeb et al. 2000 \\
\hline pMP6001 & $\begin{array}{l}\text { pRL1063a-based plasmid recovered from chromosomal DNA of PCL1113 after di- } \\
\text { gestion with EcoRI, Km }{ }^{R}\end{array}$ & This study \\
\hline pMP6002 & $\begin{array}{l}\text { pRL1063a-based plasmid recovered from chromosomal DNA of PCL1119 after di- } \\
\text { gestion with EcoRI, } \mathrm{Km}^{\mathrm{R}}\end{array}$ & This study \\
\hline pMP6003 & $\begin{array}{l}\text { pRL1063a-based plasmid recovered from chromosomal DNA of PCL1117 after di- } \\
\text { gestion with ClaI, } \mathrm{Km}^{\mathrm{R}}\end{array}$ & This study \\
\hline pMP6004 & $\begin{array}{l}\text { pRL1063a-based plasmid recovered from chromosomal DNA of PCL1120 after di- } \\
\text { gestion with EcoRI, Km }{ }^{\mathrm{R}}\end{array}$ & This study \\
\hline pMP6008 & $\begin{array}{l}\text { pBluescript containing a } 6.0-\mathrm{kb} E c o \mathrm{RI} \text { chromosomal fragment with the terminal part } \\
\text { of phzG and the complete } p h z H \text { gene } \mathrm{Cb}^{\mathrm{R}}\end{array}$ & This study \\
\hline pMP6010 & $\begin{array}{l}\text { pIC20R with a HindIII 0.3-kb internal polymerase chain reaction fragment of } p h z H \\
\text { and a tetracycline marker from pMP5000 inserted in the multicloning site with } \\
\text { SphI-SalI, Tc } \mathrm{C}^{\mathrm{R}}, \mathrm{Cb}^{\mathrm{R}}\end{array}$ & This study \\
\hline pMP6011 & pIC20R containing $\mathrm{P}_{\mathrm{tac}}-p h z H, \mathrm{Cb}^{\mathrm{R}}$ & This study \\
\hline pMP6012 & pME6010 containing $\mathrm{P}_{\text {tac }}-p h z H, \mathrm{Tc}^{\mathrm{R}}$ & This study \\
\hline pMP6013 & pIC20R containing $\mathrm{P}_{\mathrm{lac}}-p h z H, \mathrm{Cb}^{\mathrm{R}}$ & This study \\
\hline pMP6014 & pME6010 containing $\mathrm{P}_{\mathrm{lac}}-p h z H, \mathrm{Tc}^{\mathrm{R}}$ & This study \\
\hline
\end{tabular}


in the tomato- $F$. oxysporum bioassay. The introduction of the PCA gene cluster under a constitutive $\mathrm{P}_{\text {tac }}$ promoter into a wild-type, nonproducing $P$. fluorescens strain significantly improved the ability to reduce damping-off disease of pea seedlings caused by P. ultimum (Timms-Wilson et al. 2000). In a previous paper, we showed that the in vitro activity of PCA toward $F$. oxysporum f. sp. radicis-lycopersici is restricted to $\mathrm{pH}$ values below 5.7, whereas PCN also is active at neutral $\mathrm{pH}$ (Chin-A-Woeng et al. 1998). This indicates that the carboxamide group may have a large impact on the performance of biocontrol strains under certain soil and rhizosphere $\mathrm{pH}$ conditions. In this paper, we report the identification of the PCN biosynthetic genes of strain PCL1391, with emphasis on $p h z H$, a novel phenazine biosynthetic gene, which is responsible for the presence of the 1carboxamide group. The essential role of the carboxamide group in biocontrol is shown by the loss of biocontrol of a phzH mutant of strain PCL1391. Moreover, we show that transfer of the $p h z H$ gene to the PCA-producing strains $P$. fluorescens 2-79 and P. aureofaciens 30-84 results in the production of PCN rather than PCA and in the efficient suppression of tomato foot and root rot, thereby extending the biocontrol abilities of these strains.

\section{RESULTS}

\section{Isolation and characterization of phenazine biosynthetic mutants.}

Screening of a transposon mutant library of PCL1391 (Table 1) consisting of $18,000 \operatorname{Tn} 5$ lux $A B$ insertion mutants resulted in selection of PCL1120 that lacked green pigmentation but retained yellow pigmentation, indicating loss of the ability to produce PCN. Production of phenazine compounds by this strain was demonstrated with thin-layer chromatography (TLC), high-pressure liquid chromatography (HPLC), and nanoelectro-spray tandem mass spectrometry. Strain PCL1120 accumulated a compound with a $\mathrm{R}_{f}$ value similar to that of authentic PCA, which was produced in an amount similar to the amount of PCN produced by the wild-type strain. Phenazine fractions were collected with HPLC (Fig. 1A) and analyzed with nanoelectrospray mass spectrometry (Fig. 1B). A clear $\mathrm{M}+\mathrm{H}^{+}$pseudomolecular ion was observed at $\mathrm{m} / \mathrm{z}, 225$, corresponding to PCA, whereas a very minor ion at $\mathrm{m} / \mathrm{z}, 224$, which would correspond to PCN, was not above background levels. The identity of the ion at $\mathrm{m} / z, 225$ arising from PCA was confirmed when generating a fragment ion spectrum (Fig. 1C) by colliding the ion at $\mathrm{m} / \mathrm{z} 225$ with argon. The fragment
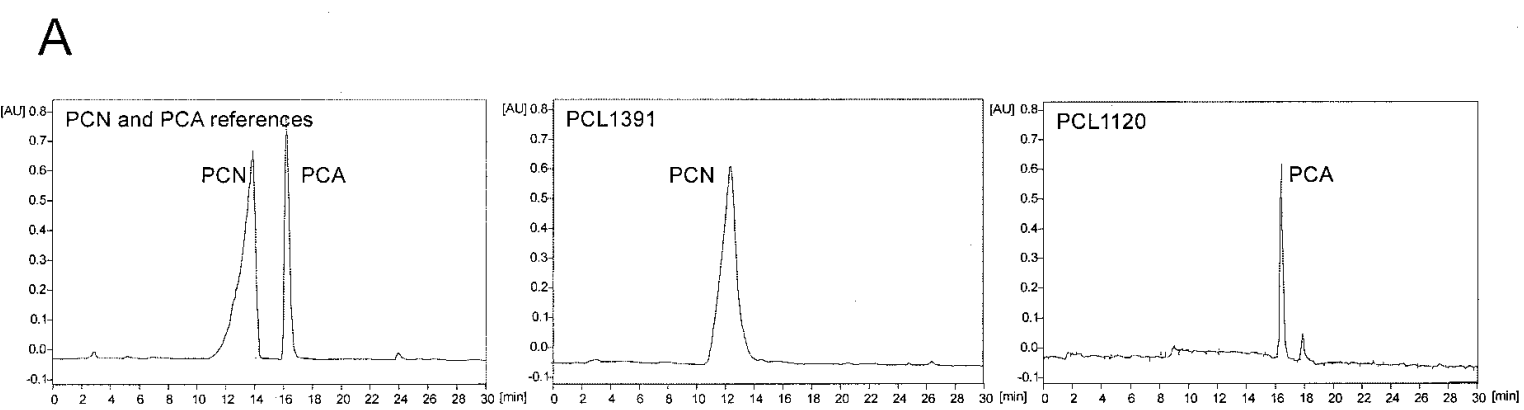

B
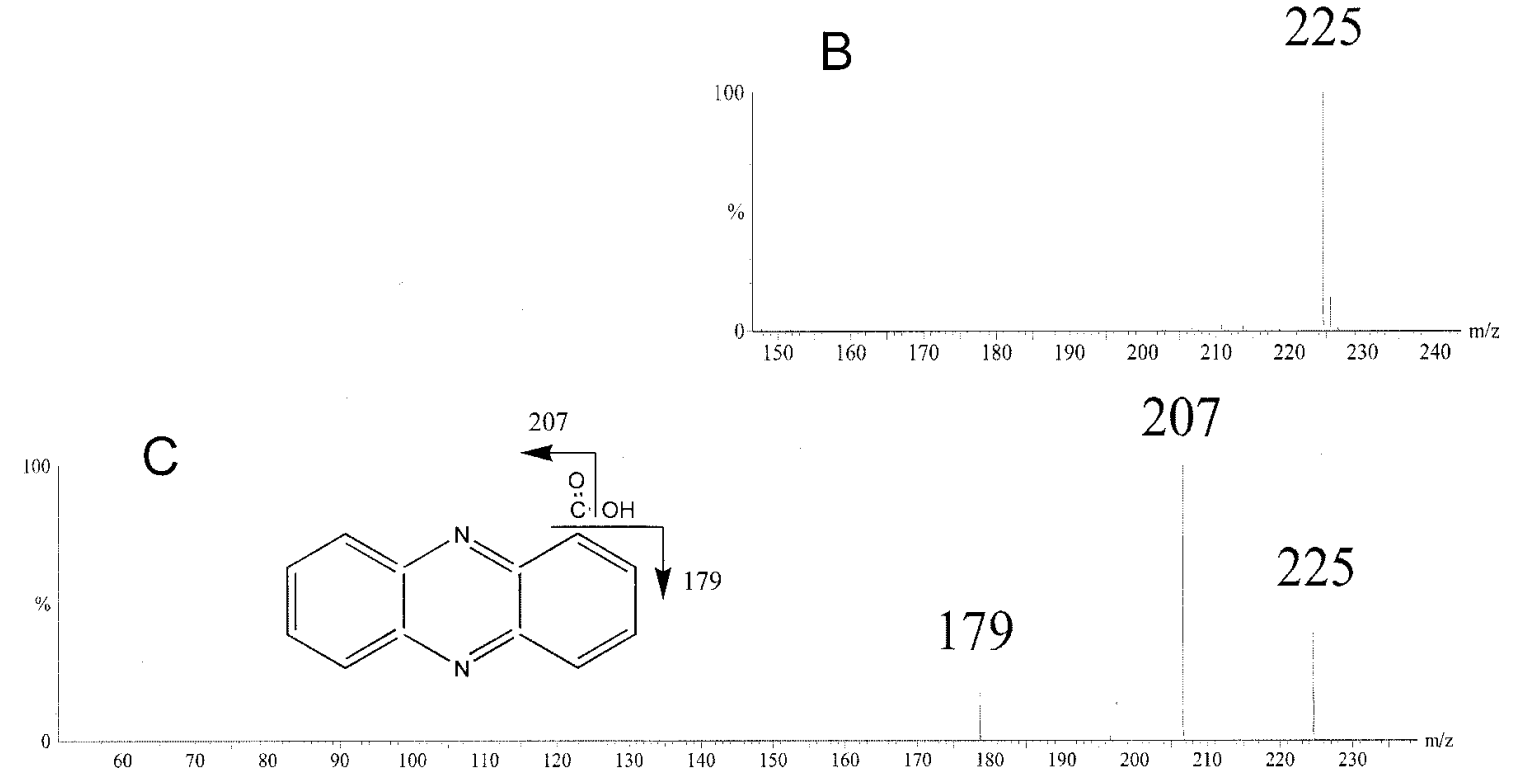

Fig. 1. Analysis of phenazines produced by wild-type Pseudomonas chlororaphis PCL1391 and a phzH mutant derivative. A, C18 reverse-phase highpressure liquid chromatographic separation of toluene extracts from 3-day old culture supernatants of wild-type strain PCL1391 and its $p h z H$ mutant PCL1120. B, Mass spectrum obtained from a toluene extract of culture supernatant of strain PCL1120. C, Fragment ion spectrum of the ion at $m / z$ 225, which was detected in culture supernatant extracts of PCL1120 (B). Insert: fragmentation scheme for phenazine-1-carboxylic acid. PCN: phenazine-1carboxamide; PCA: phenazine-1-carboxylic acid; AU: absorbance units. 
ions at $\mathrm{m} / \mathrm{z}, 207$ and 179 correspond to the acylium ion and the phenazine ring, respectively (Fig. 1C) (Chin-A-Woeng et al. 1998). A fragment ion spectrum obtained from $\mathrm{m} / \mathrm{z} 224$ (not shown) was indistinguishable from a background spectrum.

Previously, three mutant strains, PCL1113, PCL1117, and PCL1119, which are completely unable to produce a phenazine as judged from HPLC and silica TLC analyses, were isolated (Chin-A-Woeng et al. 1998). An in vitro screen was used for antifungal activity in a petri dish assay at $\mathrm{pH} 7.0$ (Geels and Schippers 1983), and strains PCL1113, PCL1117, and PCL1119 (Table 2) had lost their antagonistic activity against $F$. oxysporum f. sp. radicis-lycopersici, V. albo-atrum, $R$. solani, and $P$. ultimum. The PCA-producing strain PCL1120, however, retained its activity, which was comparable to that of the wild type (data not shown). Apart from PCN production, the four mutants retained the production of hydrogen cyanide, chitinase, protease, and lipase and were not impaired in colonization (data not shown).

\section{Nucleotide sequence of the complete PCN biosynthetic operon of $P$. chlororaphis PCL1391 and deduced amino acid sequences.}

The organization of the complete biosynthetic gene cluster of $P$. chlororaphis was determined by nucleotide sequencing of the flanking regions of the transposon insertions present in pMP6001, pMP6003, pMP6002, and pMP6004 obtained from mutants PCL1113, PCL1117, PCL1119, and PCL1120, respectively. Computer analysis revealed that the complete cluster consists of eight genes, $p h z A$ through $p h z H$ (GenBank accession no. AF195615). The nomenclature of the $p h z A$ through $p h z G$ genes follows that of the genes for PCA biosynthesis in P. fluorescens 2-79 (Mavrodi et al. 1998). The mutants PCL1113, PCL1117, PCL1119, and PCL1120 appeared to have Tn5 transposon insertions in their $p h z F, p h z C, p h z B$, and $p h z H$ genes, respectively (Fig. 2). A putative terminator sequence was identified downstream of the $p h z H$ gene. The orientation of the eight open reading frames (ORFs) and the absence of intercistronic regions containing promoter or terminator sequences suggest that these genes form a single transcriptional unit (Fig. 2). In addition, $p h z D$ and $p h z E$ as well as $p h z F$ and $p h z G$ overlap each other with four base pairs. The $p h z H$ gene is a novel $p h z$ gene that, to date, is unique to $P$. chlororaphis PCL1391. The other genes, phzA through $p h z G$, are 73 to $93 \%$ identical with the genes of the PCA biosyn-

Table 2. Secretion of phenazines by Pseudomonas chlororaphis PCL1391 and derivatives

\begin{tabular}{lccc}
\hline Strain & Mutated gene & PCA $^{\mathbf{a}}$ & PCN $^{\mathbf{b}}$ \\
\hline PCL1391 & Wild type & $-^{\mathbf{c}}$ & + \\
PCL1113 & $p h z F$ & - & - \\
PCL1117 & $p h z C$ & - & - \\
PCL1119 & $p h z B$ & - & - \\
PCL1120 & $p h z H$ & + & - \\
PCL1121 & $p h z H$ & + & - \\
\hline
\end{tabular}

a PCA: phenazine-1-carboxylic acid (PCA) secretion determined by extraction of culture supernatant with toluene, followed by thin-layer chromatography (TLC) analyses.

${ }^{b}$ PCN: phenazine-1-carboxamide secretion determined by extraction of culture supernatant with toluene followed by TLC analyses.

${ }^{c}$ PCA is produced in very minor amounts as compared to production of PCN after overnight growth in King's medium B. thetic operon of P. fluorescens 2-79 (Mavrodi et al. 1998) and 90 to $96 \%$ homologous with those of $P$. aureofaciens $30-84$ (Pierson et al. 1995), both of which produce PCA as the main phenazine derivative (Table 3 ). In these strains, a terminator sequence is located downstream of the $p h z G$ gene, indicating that this gene is the last gene of the operon (Mavrodi et al. 1998). The nucleotide sequence also has an overall identity of 70 to $80 \%$ to the phenazine biosynthetic clusters in P. aeruginosa PAO1 (nucleotide sequence obtained from GenBank database, accession no. AF005404) (Stover et al. 2000). These biosynthetic clusters consist of $p h z A$ through $p h z G$ genes and are assumed to direct phenazine production in this strain (Table 3). The genes downstream of the $p h z G$ genes in strain PAO1 do not show sequence homology with $p h z H$. The homology of each ORF and its possible function are summarized in Table 3. On the basis of similarities with enzymes in the GenBank sequence database, Pierson et al. designated functions to a number of these gene products in a hypothetical phenazine biosynthetic pathway (Pierson et al. 1995).

\section{Characterization of the $p h z H$ gene.}

HPLC and mass spectrometric analyses (Fig. 1) of culture supernatant extracts of mutant PCL1120 show that the Tn5 insertion in the $\mathrm{phzH}$ gene results in a mutant unable to produce PCN. Instead, the mutant produces the putative precursor PCA in amounts similar to those of PCN produced by the wild type. A yellow pigment is visible in PCL1120 colonies as a result of the production of PCA (not shown), but not the green pigment $(\mathrm{PCN})$ observed for the parental strain (Gerber 1984).

Additionally, a polymerase chain reaction (PCR) fragment with an internal part of the $p h z H$ gene was cloned into pIC20R, resulting in pMP6010, and used as a suicide vector in a $P$. chlororaphis PCL1391 background to obtain an independent $\mathrm{phzH}$ mutant (PCL1121) by homologous recombination. All phenotypic traits of the independent mutant PCL1121 were identical to those of the originally isolated $\mathrm{phzH}$ mutant PCL1120 (Table 2). Absence of production of PCN and accu-

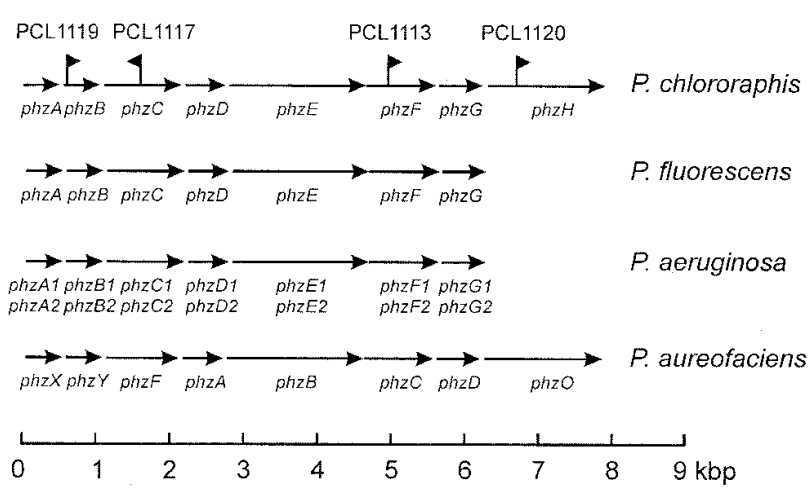

Fig. 2. Schematic presentation of the phenazine biosynthetic operon of Pseudomonas chlororaphis PCL1391. Location and direction of the Tn5luxAB insertions of mutant derivatives, PCL1119, PCL1117, PCL1113, and PCL1120 are indicated by a flag. The biosynthetic cluster was deduced from data obtained by nucleotide sequencing of the regions flanking the transposons. For comparison, the phenazine biosynthetic operons of Pseudomonas fluorescens 2-79 (Mavrodi et al. 1998), Pseudomonas aeruginosa PAO1 (GenBank accession no. AF005404), and Pseudomonas aureofaciens 30-84 (Pierson et al. 1995) are included. 
mulation of PCA by PCL1121 was confirmed by TLC (data not shown) and mass spectrometry (data not shown). The identity of the product formed by PCL1121 was determined with nanoelectrospray mass spectrometry. The mass spectrum, again, has a major ion at $\mathrm{m} / \mathrm{z} 225$ for PCA and no discernible ion at $\mathrm{m} / z 224$ for PCN. Collision-induced dissociation (CID) tandem mass spectra were obtained from $\mathrm{m} / \mathrm{z} 224$ and 225. The spectrum from $\mathrm{m} / \mathrm{z}, 225$ (indistinguishable from that obtained from the PCA from strain PCL1120) (Fig. 1C) is diagnostic for PCA, whereas the spectrum from $\mathrm{m} / \mathrm{z} 224$ (not shown) was indistinguishable from a background spectrum.

Screening a chromosomal plasmid library of strain PCL1391 with an internal 0.3-kb PCR fragment of the $p h z H$ gene yielded a 6-kb clone harboring the terminal part of the $p h z G$ gene and the complete $p h z H$ gene of strain PCL1391. The deduced amino acid sequence of the novel PCN biosynthetic $p h z H$ gene predicts a protein of 614 amino acids. The overall protein sequence has the highest similarity to the products of Bacillus subtilis yucB (36\%; accession no. Z93940), yisO (36\%; accession no. Y09476), asnB (27\%; accession no. AF008220), and asnH (27\%; accession no. P42113) genes. These sequences all share homology with asparagine synthetases. The nucleotide sequences of these genes were derived from genome-sequencing projects, and the exact functions of these genes have not yet been established. Other homologies include asparagine synthetases of Rattus norvegicus (27\%; accession no. 2207183A), Oryzae sativa (25\%; accession no. Q43011), Escherichia coli (25\%; accession no. P22106), and Homo sapiens (25\%; accession no. AC005326). Several domains characteristic for class II amidotransferases were identified. The N-terminal domain of $\mathrm{PhzH}$ has a motif that is conserved in class II glutamine amidotransferases (Fig. 3). In addition, the catalytic cysteine $\left(\mathrm{Cys}^{1}\right)$, which is characteristic for the class II glutamine amidotransferase domain, is present in $\mathrm{PhzH}$ (Massiere and Badet 1998; data not shown). The C-terminal domain of PhzH characteristically harbors motifs for asparagine synthetases (Fig. $3)$.
Complementation of PCA-accumulating mutants by phzH.

In order to express the single $p h z H$ gene for complementation of the PCA-producing mutants, the lac $\left(\mathrm{P}_{\text {lac }}\right)$ and $\operatorname{tac}\left(\mathrm{P}_{\mathrm{tac}}\right)$ promoters were used to express the $p h z H$ gene at a constitutive level in Pseudomonas spp. After PCR, the nucleotide sequences of the obtained fragments were verified and the $\mathrm{P}_{\mathrm{tac}}-p h z H$ and $\mathrm{P}_{\mathrm{lac}}-p h z H$ fragments were transferred to the rhizosphere-stable vector pME6010 (Heeb et al. 2000), resulting in pMP6012 and pMP6014, respectively. PCN production was restored partially in the PCN mutant PCL1120 complemented with plasmids pMP6012 (PCL1145) or pMP6014 (PCL1143), as demonstrated with TLC (Fig. 4, lane 3) and nanoelectrospray mass spectrometry. The mass spectrum obtained from the product from PCL1145 $\left(\mathrm{P}_{\mathrm{lac}}-p h z H\right)$ had a major ion at $\mathrm{m} / \mathrm{z}, 224$ and a less intense ion at $\mathrm{m} / \mathrm{z}, 225$, corresponding to PCN and PCA, respectively. The identity of the species that gave rise to the ion at $m / \mathrm{z} 224$ was demonstrated when recording a fragmentation spectrum of a $\mathrm{m} / \mathrm{z} 224$ collision with argon. Fragment ions at $m / \mathrm{z} 207$ (the acylium ion) and 179 (the phenazine ring), arising by losses of $17 \mathrm{Th}$ for $\mathrm{NH}_{3}$ and 45 Th for the amide moiety, were produced. Similarly, the identity of the ion at $\mathrm{m} / \mathrm{z} 225$ was demonstrated when recording a CID spectrum. The same fragment ions that were in the ion at $m / z 224$ were observed, but this time they were the result of a loss of $18 \mathrm{Th}$ for $\mathrm{H}_{2} \mathrm{O}$ and $46 \mathrm{Th}$ for the carboxylic acid moiety, demonstrating that $\mathrm{m} / \mathrm{z}, 225$ arises from PCA.

\section{Biocontrol by PCA-producing phzH mutants.}

To analyze the role of the carboxamide moiety of PCN in biocontrol, $p h z H$ mutant PCL1120 was tested in a tomato- $F$. oxysporum f. sp. radicis-lycopersici biocontrol system. When no bacteria were applied to the tomato seeds, $74 \%$ of the plant root systems showed root rot after 16 days of growth in soil infected with $F$. oxysporum, whereas coating with cells of the wild-type biocontrol strain PCL1391 reduced disease incidence to $33 \%$ (Fig. 5A). Although strain PCL1120 $(p h z H:: \operatorname{Tn} 5 \operatorname{lu} x A B)$ was able to inhibit fungal growth in petri

Table 3. Identities of the phz genes of Pseudomonas chlororaphis PCL1391 to those from other Pseudomonas spp.

\begin{tabular}{|c|c|c|c|c|}
\hline \multirow[b]{2}{*}{ Gene } & \multicolumn{3}{|c|}{ Homology (\% identity) to P. chlororaphis PCL1391 } & \multirow[b]{2}{*}{ Identity with GenBank enzymes (\%) } \\
\hline & P. fluorescens 2-79 & P. aureofaciens 30-84 & P. aeruginosa PAO1 & \\
\hline$\overline{p h z A}$ & phzA (90) & $p h z X^{\mathrm{a}}(95)$ & phzAl (67) & No similarity \\
\hline & & & phzA2 (68) & \\
\hline$p h z B$ & $p h z B(73)$ & $p h z Y^{\mathrm{a}}(96)$ & phzB1 (78) & No similarity \\
\hline & & & $p h z B 2(78)$ & \\
\hline$p h z C$ & $p h z C(85)$ & $\operatorname{phz} F(95)$ & phzCl (74) & $\begin{array}{l}\text { 3-deoxy-D-arabinoheptulosonate-7-phosphate synthase from } \\
\text { Streptomyces }\end{array}$ \\
\hline $\operatorname{phz} D$ & $\operatorname{phz} D(92)$ & phzA (94) & $\begin{array}{l}\text { phzD1 (79) } \\
\text { phzD2 (79) }\end{array}$ & $\begin{array}{l}\text { 2,3-dihydro-2,3-dihydroxybenzoate synthase (isochorismatase) } \\
(47 \%)^{\mathrm{b}}\end{array}$ \\
\hline$p h z E$ & $\operatorname{phzE}(92)$ & $\operatorname{phzB}(95)$ & $\begin{array}{l}\text { phzE1 (76) } \\
\text { phzE2 (76) }\end{array}$ & Anthranilate synthase $\operatorname{trp} E(50 \%)^{\mathrm{b}}$ \\
\hline$p h z F$ & $p h z F(93)$ & $p h z C(96)$ & $\begin{array}{l}p h z F 1(76) \\
p h z F 2(76)\end{array}$ & $\begin{array}{l}\text { Thymidylate synthase } \mathrm{e}^{\mathrm{b}} \text { and } \mathrm{LmbX} \text { protein of Streptomyces lin- } \\
\text { colnensis (29\%) }\end{array}$ \\
\hline$p h z G$ & $p h z G(92)$ & $\operatorname{phz} D(90)$ & $\begin{array}{l}\text { phzG1 (71) } \\
\text { phzG2 (71) }\end{array}$ & Pyridoxamine- $5^{\prime}$-phosphate oxidase $(33 \%)^{\mathrm{b}}$ \\
\hline$p h z H$ & $\mathrm{~N}^{\mathrm{c}}$ & $\mathrm{N}^{\mathrm{c}}$ & $\mathrm{N}^{\mathrm{c}}$ & Asparagine synthetases (27\%) \\
\hline $\mathrm{N}^{\mathrm{c}}$ & $\mathrm{N}^{\mathrm{c}}$ & $p h z O$ & $\mathrm{~N}^{\mathrm{c}}$ & Aromatic monooxygenase (35-40\%) \\
\hline
\end{tabular}


dishes to the same extent as the wild type (data not shown), it appeared to have lost its biocontrol ability in the tomato- $F$. oxysporum test system (Fig. 5A). Seed coating with cells of mutant PCL1120 did not reduce disease significantly (72\% diseased plants). When the $p h z H$-complemented strain PCL1143 (PCL1120 $\mathrm{P}_{\mathrm{lac}}-p h z H$ ) was applied, however, significant restoration of disease control resulted $(42 \%$ of diseased plants) (Fig. 5A).

\section{Transfer of $p h z H$ to PCA-producing strains and the effect on biocontrol.}

To evaluate the function of $\mathrm{PhzH}$ and extend the biocontrol ability of PCA-producing strains, pMP6012 carrying $\mathrm{P}_{\mathrm{tac}}-$ $p h z H$ was transferred to the PCA-producing wild-type strains $P$. fluorescens 2-79 (Thomashow and Weller 1988) and $P$. aureofaciens 30-84 (Pierson et al. 1995), resulting in strains PCL1147 and PCL1149, respectively. Analysis of toluene extracts of spent culture supernatant of 72-h cultures of these strains showed that PCL1147 (Fig. 4, lane 5) and PCL1149 (Fig. 4, lane 7) produced PCN instead of PCA (Fig. 4, lanes 4 and 6). The production of PCN was determined quantitatively with HPLC (results not shown), and PCL1147 and PCL1149 produced approximately twice the amount $(0.29 \mathrm{~g}$ per liter $)$ produced by strain PCL1391 (0.15 g per liter), whereas PCA was below detectable levels.

In the tomato- $F$. oxysporum bioassay, the PCA-producing biocontrol strains $P$. fluorescens 2-79 and P. aureofaciens 30-
84 do not inhibit tomato foot and root rot (Fig. 5B and C), whereas the PCN-producing strain PCL1391 reduces disease formation (Fig. 5A). To investigate whether the amidation of the carboxylate moiety of PCA changes the biocontrol abilities of strains 2-79 and 30-84, strains PCL1147 and PCL1149 were tested in the tomato- $F$. oxysporum system. In biocontrol experiments conducted with strain $2-79$, this strain did not inhibit tomato foot and root rot compared with the control in which no bacteria were applied onto the seeds (Fig. 5B). In strain PCL1147, however, the 2-79 derivative producing PCN reduced the number of diseased plants efficiently in these tests (Fig. 5B). Likewise, the PCN-producing 30-84 derivative PCL1149 controlled disease formation, whereas the wild-type strain 30-84 did not (Fig. 5C).

\section{DISCUSSION}

P. chlororaphis PCL1391 produces PCN (Chin-A-Woeng et al. 1998). In a tomato- $F$. oxysporum test system, strain PCL1391 is active, in contrast to PCA-producing strains (Chin-A-Woeng et al. 1998). These data suggest that the 1carboxamide functional group could be of major importance for the suppression of tomato foot and root rot (Chin-AWoeng et al. 1998). The genetic basis for the presence of the 1-carboxamide group was elucidated by the identification of the PCN biosynthetic operon (Fig. 2). In order to identify the PCN biosynthetic genes of $P$. chlororaphis, a number of

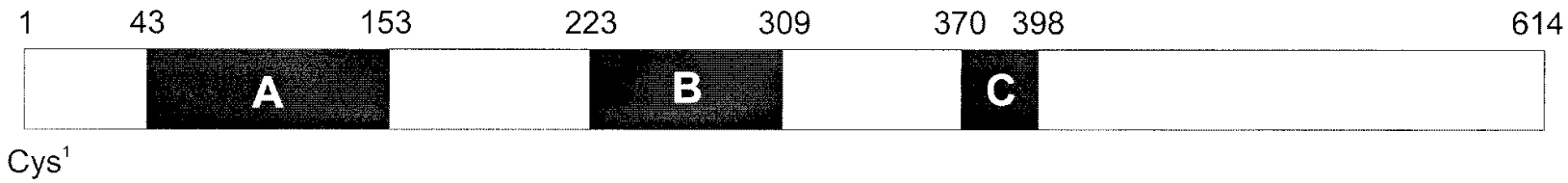
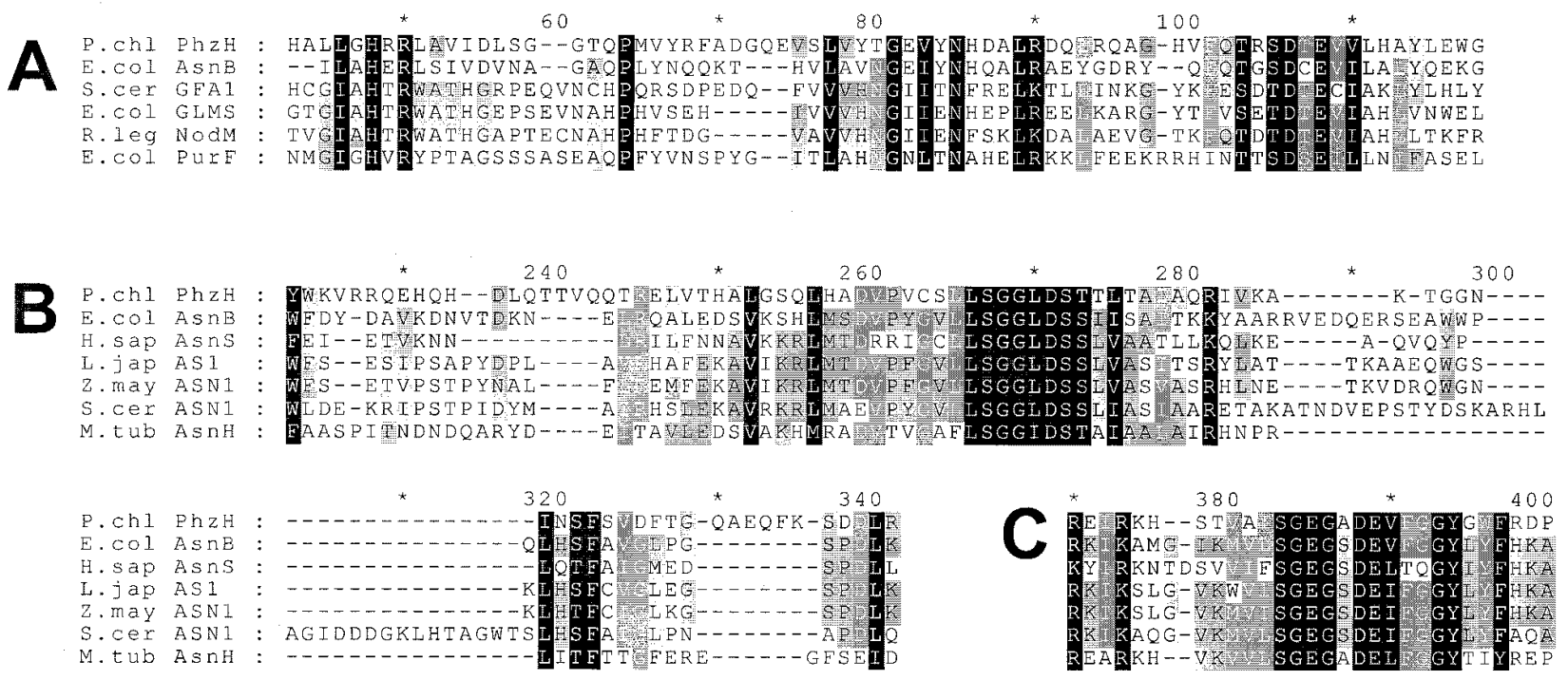

Fig. 3. Identification of class II glutamine amidotransferase and asparagines synthetase motifs in the PhzH protein. Alignment of the deduced protein sequence of the $p h z H$ gene with sequences in the Pfam protein domain database shows a class II glutamine amidotransferase motif in the N-terminal part of the protein (A). The C-terminal part of PhzH harbors two conserved asparagine synthetase motifs (B and C). For the alignment of the class II glutamine amidotransferase domain (A), the protein sequences of asparagine synthetase (AsnB), glucosamine-fructose-6-phosphate aminotransferase (GLMS), and amidophosphoribosyltransferase (PurF) of Escherichia coli (E. col), glucosamine-fructose-6-phosphate aminotransferase (GFA1) of Saccharomyces cerevisiae (S. cer), and NodM of Rhizobium leguminosarum bv. viciae (R. leg) were used. For the alignment of the class II glutamine amidotransferase domains the protein sequences of asparagine synthetases of E. coli, Homo sapiens (H.sap), Lotus japonicus (L. jap), Zea mays (Z. may), and Mycobacterium tuberculosis (M. tub) were used. Conserved amino acids are boxed. Black and gray boxes represent amino acids that are conserved or fall within the same similarity group. 
$\operatorname{Tn} 5$ lux $A B$ mutants impaired in phenazine production were isolated and characterized. The most interesting mutant was PCL1120, which is impaired in the production of PCN but does produce PCA, which was shown with nanoelectrospray tandem mass spectrometry (Fig. 1B and C). This is consistent with the observed colony pigmentation and data obtained from HPLC (Fig. 1A) and TLC analyses (Fig. 4). Nucleotide sequence analysis of the regions flanking the Tn5 insertion in PCL1120 shows that the phz biosynthetic operon of strain PCL1391 possesses an additional and novel $p h z H$ gene not present in other phenazine-producing biocontrol strains (Fig. $2)$. Recently, the $p h z O$ gene, encoding an aromatic monooxygenase that is needed for the conversion of PCA to 2hydroxylated phenazines, was located following the last gene of the core phenazine biosynthetic cluster $(p h z G)$ in $P$. aureofaciens 30-84 (Delaney et al. 2001).

The similarity of the $p h z H$ product to asparagine synthetases (Massiere and Badet 1998) (Fig. 3), the accumulation of PCA in $p h z H$ mutant PCL1120, and the loss of PCN production observed in PCL1120 as the result of the Tn5 insertion strongly suggests that $\mathrm{PhzH}$ functions in the conversion of PCA to PCN. The mutant phenotype was confirmed by the construction of $p h z H$ mutant PCL1121 by homologous recombination (Fig. 4). Asparagine synthetases belong to the class II glutamine amidotransferases, and asparagine synthetases specifically catalyze the transfer of the amido nitrogen of glutamine to aspartate to produce glutamate and asparagine (Massiere and Badet 1998). Sequence analysis of the phzH

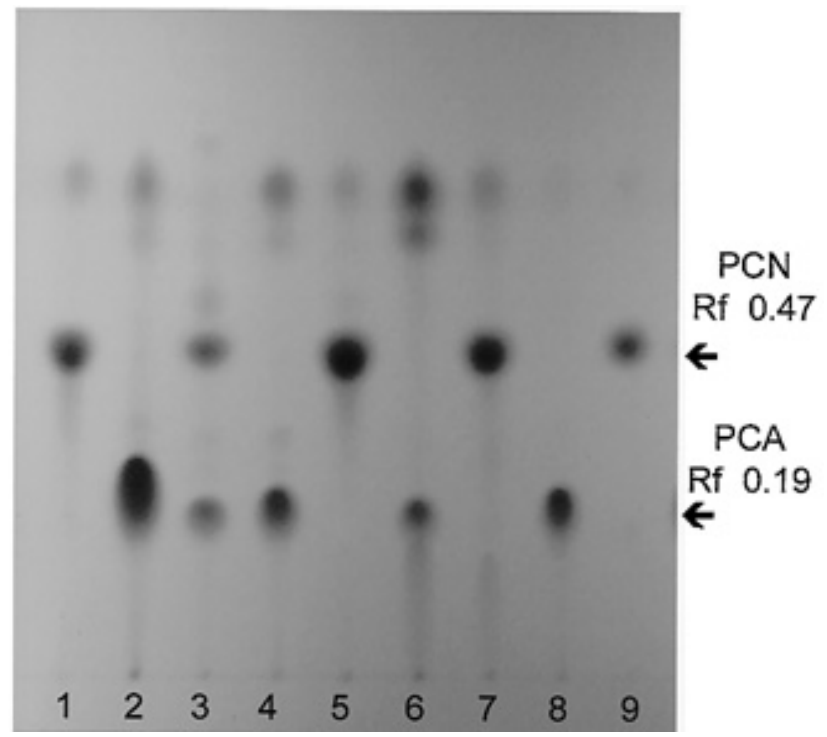

Fig. 4. Silica thin-layer chromatography (TLC) fractionation of culture supernatants of Pseudomonas chlororaphis PCL1391, mutant derivatives, and complemented mutants. Extracts of 3-day culture supernatants were made with toluene, and samples were applied directly to TLC plates after removal of the organic solvent and subsequent dissolution in acetonitrile. Phenazines were visualized by UV irradiation at $254 \mathrm{~nm}$. Lane 1: PCL1391; lane 2: PCL1120 (phzH::Tn5luxAB); lane 3: PCL1143 (PCL1120 harboring pMP6014); lane 4: Pseudomonas fluorescens 2-79; lane 5: PCL1147 ( $P$. fluorescens 2-79 harboring pMP6012); lane 6: Pseudomonas aureofaciens 30-84, lane 7: PCL1149 ( $P$. aureofaciens 30-84 harboring pMP6012), lane 8: phenazine-1carboxylic acid (PCA) standard, lane 9: phenazine-1-carboxamide (PCN) standard. gene shows that the most conserved part in the protein sequence is the $\mathrm{N}$ terminal. The presence of the catalytic domain in the $\mathrm{N}$ terminal and substrate-specificity domain in the $\mathrm{C}$ terminal is characteristic for class II glutamine amidotransferases (Massiere and Badet 1998). The observed similarities indicate that this also is the case for $\mathrm{PhzH}$. PCN production in mutant PCL1120 was restored largely by the $p h z H$ gene under control of tac or lac promoters (strains PCL1143 and PCL1145, respectively) (Fig. 4). The incomplete complementation in PCL1120 harboring the $p h z H$ gene in trans may be caused by a weak expression of the promoter in this strain. Because the production of PCN in the PCA-producing strains carry the $p h z H$ gene appeared to be slightly better with the $t a c$ promoter, we decided to use the strains harboring $\mathrm{P}_{\mathrm{tac}}-p h z H$ (pMP6012) for biocontrol experiments. The other phz genes, $p h z A$ through $p h z G$, are very similar (70 to $95 \%$ ) to the phenazine biosynthetic genes of PCA-producing species (Table 3) and appear to be sufficient for the production of PCA (Fig. 4).

Strain PCL1120 (phzH::Tn5luxAB) produces PCA and normal amounts of chitinase, protease, and $\mathrm{HCN}$ and retains its good root-colonizing ability. Although strain PCL1120 retains the same ability to inhibit fungal growth in vitro in petri dishes as does the wild type, this PCA-producing mutant appeared to lose its biocontrol activity in the tomato-F. oxysporum test system (Fig. 5A). These results show that the difference in biocontrol between $P$. chlororaphis and its PCAproducing mutant is presumably the result of the inability of the latter strain to convert the carboxylic moiety of PCA to the

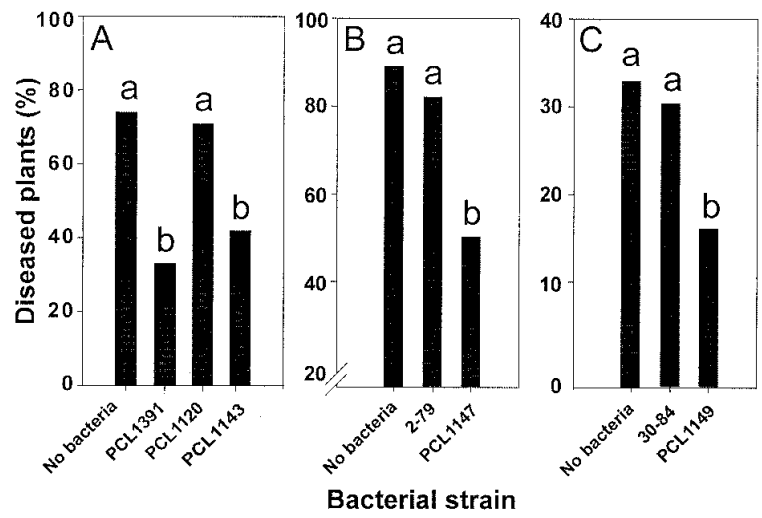

Fig. 5. Biocontrol of tomato foot and root rot by Pseudomonas spp. wild-type strains and derivatives. Tomato seeds coated with the indicated bacterial strains were sown in potting soil infected with spores of Fusarium oxysporum f. sp. radicis-lycopersici. After 16 days of growth, the plants roots were removed from the soil and the number of plants with foot and root rot was determined. In each panel, bars with the same letter are not significantly different at $\alpha=0.05$, according to the analysis of variance followed by Fisher's least significant difference test. A, Biocontrol by Pseudomonas chlororaphis PCL1391, phzH mutant PCL1120, and PCL1143 (PCL1120 harboring pMP6014 with the phzH gene under control of the lac promoter). Experiments were performed twice, with 96 plants per strain. B, Biocontrol by Pseudomonas fluorescens wild-type strain 2-79 and PCL1147 (strain 2-79 harboring pMP6012 containing the phzH gene under control of the tac promoter). The experiment was repeated three times. C, Biocontrol by Pseudomonas aureofaciens wild-type strain 30-84 and PCL1149 (strain 30-84 harboring pMP6012 containing the $\mathrm{phzH}$ gene under control of the tac promoter). The experiment was performed twice, with 96 plants per strain. 
1-carboxamide group. The difference in action between the two compounds can be explained by the different behavior of the compounds at low and neutral $\mathrm{pH}$ values (Chin-A-Woeng et al. 1998). The importance of the $p h z H$ gene and the 1carboxamide moiety has been confirmed by genetic complementation of the $p h z H$ mutant PCL1120. The introduction of $p h z H$ restored PCN production (Fig. 4) and biocontrol activity (Fig. 5A). Moreover, PCA-producing strains $P$. fluorescens 279 and $P$. aureofaciens 30-84 appeared to produce PCN after the introduction of the $p h z H$ gene. $P$. fluorescens $2-79$ and $P$. aureofaciens 30-84 harboring $\mathrm{P}_{\mathrm{tac}}-p h z H$ show efficient biocontrol ability in the tomato- $F$. oxysporum test system (Fig. $5 \mathrm{~B}$ and $\mathrm{C}$ ). In conclusion, our results show that $\mathrm{PhzH}$ is responsible for the amidation of PCA, that the 1-carboxamide group is crucial for the suppression of foot and root rot by strain PCL1391, and that the conversion of PCA to PCN can extend the biocontrol ability of strains. In addition, our studies show that genetic modification of biocontrol strains can optimize biocontrol ability.

\section{MATERIAL AND METHODS}

\section{Bacterial strains and culture conditions.}

The bacterial strains and plasmids used are listed in Table 1. King's medium B (King et al. 1954) was used routinely to culture Pseudomonas spp. strains. E. coli strains were grown in Luria-Bertani medium (Sambrook et al. 1989). F. oxysporum f. sp. radicis-lycopersici ZUM2407 (IPO-DLO, Wageningen, The Netherlands) was stock cultured on potato dextrose agar (Difco Laboratories, Detroit, MI, U.S.A.) and grown in Czapek-Dox liquid medium (Difco Laboratories) at $25^{\circ} \mathrm{C}$. Media were solidified with $1.8 \%$ agar (Difco Laboratories) when necessary. For antibiotic selection, the following were added, per $\mathrm{ml}$, where applicable: $50 \mu \mathrm{g}$ of kanamycin, $80 \mu \mathrm{g}$ of tetracycline, and $50 \mu \mathrm{g}$ of carbenicillin.

\section{DNA modifications.}

Digestion with restriction endonucleases, ligation, transformation of E. coli cells with plasmid DNA, and PCR with Pwo polymerase (Roche Molecular Biochemicals, Basel, Switzerland) were performed with standard molecular biological protocols (Sambrook et al. 1989). Plasmid transformation of Pseudomonas spp. was achieved with electroporation (1.25 kV per cm, $2.5 \mu \mathrm{F}, 200 \Omega$; Gene Pulser, Bio-Rad Laboratories, Richmond, CA, U.S.A.). Nucleotide sequencing was performed by Eurogentec (Herstal, Belgium) with AB1377based fluorescent sequencing technology. Computer analysis of protein and nucleotide sequences was carried out with Wisconsin software package version 10.0 (Genetics Computer Group, Madison, WI, U.S.A.). The DNA sequence of the entire phenazine biosynthetic operon has been submitted to GenBank as accession no. AF195615.

\section{Isolation and genetic characterization of phenazine biosynthetic mutants from a Tn5luxAB mutant library of PCL1391.}

A mutant library of PCL1391 was established with pRL1063a harboring a Tn5 transposon carrying promoterless luxAB reporter genes (Wolk et al. 1991). Transposants were screened for the loss of green and yellow pigmentation as a result of the lack of PCN production. Because the transposon contains an origin of replication that functions in E. coli, DNA flanking the transposon was recovered from the genome by excision with EcoRI or ClaI, followed by recircularization, transfer to DH5 $\alpha$, and analysis by nucleotide sequencing. Nucleotide sequencing of the flanking chromosomal regions was performed with unique primers oMP458 (5'-TACTAGATTCAATGCTATCAATGAG-3') and oMP459 (5'-AGGAGGTCACATGGAATATCAGAT- $3^{\prime}$ ) that were directed to the left and right ends of the $\operatorname{Tn} 5$ transposon.

\section{Purification and structural identification of antifungal factors.}

The supernatants of 3-day cultures were extracted with equal volumes of toluene. The remaining water phase was acidified to $\mathrm{pH} 2$ with concentrated hydrochloric acid and reextracted twice with an equal volume of toluene (Fernandez and Pizarro 1997). The two organic phases were pooled and dried by evaporation in vacuo. The dry residue was dissolved in $100 \%$ acetonitrile and fractionated with either silica TLC or HPLC. Silica TLC plates (Merck, Darmstadt, Germany) were developed in butanol-acetone (90:10 vol/vol). After development, the plates were dried and compounds were visualized under UV light $(254 \mathrm{~nm})$. Authentic PCN and PCA standards migrated in this system with $\mathrm{R}_{f}$ values of 0.47 and 0.19 , respectively. HPLC was performed with a Hypersil octadecyl silane column $(5 \mu \mathrm{m}, 250 \times 4.6 \mathrm{~mm}$; Alltech Associates, Deerfield, IL, U.S.A.) and a linear 20 to $90 \%$ (vol/vol) gradient of acetonitrile in water with a flow rate of $1 \mathrm{ml}$ per min. Samples were dissolved in $30 \%$ acetonitrile prior to injection onto the HPLC column. UV detection was performed with a RSD 2140 diode array detector (Pharmacia, Uppsala, Sweden), with wavelength scanning from 190 to $400 \mathrm{~nm}$, and 2.0-ml fractions were collected for mass spectrometry.

PCA and PCN production by wild-type, mutant, and complemented mutant strains was demonstrated with mass spectrometry in conjunction with chromatographic methods. The chemical structures of the compounds produced by wild-type and mutant strains having the same $\mathrm{R}_{f}$ values as PCA and PCN were determined with nanoelectrospray tandem mass spectrometry in the positive ion mode. Mass spectra and fragment ion spectra produced on collision of a selected precursor ion with argon gas (CID tandem mass spectra) were recorded with a Micromass hybrid quadrupole time-of-flight (Q-TOF) tandem mass spectrometer (Wythenshawe, U.K.) equipped with a ZSpray sample introduction system in a nanoflow electrospray ion source. The mass spectrometer was operated with a source temperature of $70^{\circ} \mathrm{C}$. The cone voltage was set at $25 \mathrm{~V}$, and the capillary voltage was set at 3,000 V. Argon was used as the collision gas, and the spectra were obtained with a collision energy of $20 \mathrm{eV}$. Spectra were acquired via the TOF analyser and integrated every $2.4 \mathrm{~s}$ over the $\mathrm{m} / \mathrm{z}, 50$ to 300 range. Data were recorded and processed with MassLynx software, version 3.1 (Micromass). Mass calibration was performed by multiple ion monitoring of singly charged sodium and cesium iodide signals. The samples were dissolved in 0.5 to $1.0 \mathrm{ml}$ of acetonitrile-water (1:1) containing $0.1 \%$ formic acid. Samples were delivered to the ion source with a fused silica continuous flow sample introduction system and a syringe pump that delivers sample solution at a rate of $1 \mu \mathrm{l}$ per min. Between samples, the capillary was thoroughly rinsed with the same solvent as well as undiluted for- 
mic acid, after which the system was reflushed with sample solvent prior to the injection of the next sample. Blank spectra (solvent only) were recorded before injection of each new sample to be certain that no contamination or carryover with the previous sample had occurred.

\section{Isolation of the complete $p h z H$ gene and construction of a phzH mutant.}

Oligonucleotide primers oMP500 (5'-CCCAAGCTTCGGTGGACTTCACTGGC-3') and oMP501 (5'-CCCAAGCTTGGCACACGTACCTCAAGGCT-3'), based on the sequences of the recovered flanking regions of $p h z H$ mutant PCL1120, were used to obtain a 0.3-kb DNA fragment (nucleotide positions 879 to 1,172 of the $p h z H$ gene) by PCR. The primers contained restriction enzyme sites for HindIII (underlined), and the fragment was used to probe a plasmid library of chromosomal EcoRI fragments of PCL1391 in pBluescript (Stratagene, La Jolla, CA, U.S.A.) to isolate a clone containing the complete $p h z H$ gene.

The same PCR product was cloned into pIC20R with HindIII. A tetracycline marker obtained from pMP5000 was inserted into the multicloning site of pIC20R with $S p h \mathrm{I}$ and SalI. The resulting plasmid, pMP6010, was used as a suicide vector to obtain an independent $p h z H$ mutant of strain PCL1391 by homologous recombination.

\section{Expression of the $p h z H$ gene under control of the tac and lac promoters.}

The $t a c$ promoter was cloned in front of the $p h z H$ gene of strain PCL1391 with a 100-mer oligonucleotide primer oMP467 (5'-GGGGAATTCTTGACAATTAATCATCGGCT CGTATAATGTGTGGAATTGTGAGCGGATAACAATTTTC ACACAGGAAACAGCTAAATGTGCGGTCTCACAGGAT GGGTAGACTATACGC-3') and primer oMP466 (5'-GGA ATTCTGGCCGGGCCTGCCGTG-3'). Primer oMP467 contained an EcoRI recognition site (underlined), followed by the tac promoter sequence (Amann et al. 1983). The remainder of the primer was identical to the sequence of $p h z H$ from positions -4 to +34 (start codon in bold). Primer oMP466 was directed 35 nucleotides downstream of the $p h z H$ ORF. The 1.9-kb fragment obtained with oMP466 and oMP467 was cloned into pIC20R (resulting in pMP6011) and pME6010 (Heeb et al. 2000) (resulting in pMP6012). The lac promoter was cloned in front of the $p h z H$ gene with oligonucleotide primer oMP502 (5'-GGAATTCTTTACACTTTATGCTTCCGGCTCGTATGTTGTGTGGAATTGCTAGCGGATAACAATTTCACACAGGAACCAGACATATGTGCGGTCTCACAGGATTGGTAGACTATACGC-3') and oMP466. Primer oMP502 contained an EcoRI recognition site (underlined), followed by the E. coli lac promoter sequence (Gilbert and Maxam 1973). The remainder of the primer was identical to the sequence of $\mathrm{phzH}$ from positions -4 to +34 . The fragment obtained with oMP502 and oMP466 was cloned into pIC20R (resulting in pMP6013) and pME6010 (resulting in pMP6014). To test for possible mutations introduced by the PCR, the nucleotide sequence of the resulting PCR product was determined with standard M13 -20 and reverse primers for sequencing (Sambrook et al. 1989). The resulting constructs were transferred to various wild-type and mutant strains by electroporation.

\section{Biocontrol experiments.}

Tomato-Fusarium oxysporum f. sp. radicis-lycopersici bioassays were performed with the experimental setup described previously (Chin-A-Woeng et al. 1998). Briefly, seeds were coated with the biocontrol bacteria and sown in pots containing potting soil infected with spores of $F$. oxysporum f. sp. radicis-lycopersici $\left(2.0 \times 10^{6}\right.$ spores per $\left.\mathrm{kg}\right)$. Plants were grown in a greenhouse at $21^{\circ} \mathrm{C}$ with $70 \%$ relative humidity and $16 \mathrm{~h}$ daylight. At least eight replications containing 12 plants were inoculated with each test strain. After 16 days, the plant roots were examined for browning and lesions. Data were analyzed for significance with analysis of variance, followed by Fisher's least significant difference test $(\alpha=0.05)$, with SPSS software (Chicago, IL, U.S.A.). All experiments were performed at least twice.

\section{ACKNOWLEDGMENTS}

We thank I. H. M. Mulders, L. C. Dekkers, and D. de Witt for their technical assistance in the biocontrol experiments. We thank S. Heeb and D. Haas for kindly providing us with the pME6010 cloning vector. T. F. C. Chin-A-Woeng was supported partially by EU-BIOTECH project grant BI04-CT96.0181. J. E. Thomas-Oates gratefully acknowledges financial support from the EPSRC for a Ph.D. studentship (for SN) from the Higher Education Funding Council for England, with additional support from Smith Kline Beecham, UMIST, the University of Wales College of Medicine, Chugai Pharmaceuticals (S. J. Gaskell and R. J. Beynon) for the purchase of the Q-TOF, and PerSeptive Biosystems for the loan of the Mariner to the Michael Barber Centre for Mass Spectrometry.

\section{LITERATURE CITED}

Amann, E., Brosius, J., and Ptashne, M. 1983. Vectors bearing a hybrid trp-lac promoter useful for regulated expression of cloned genes in Escherichia coli. Gene 25:167-178.

Anjaiah, V., Koedam, N., Nowak-Thompson, B., Loper, J. E., Höfte, M., Tambong, J. T., and Cornelis, P. 1998. Involvement of phenazines and anthranilate in the antagonism of Pseudomonas aeruginosa PNA1 and Tn5 derivatives toward Fusarium spp. and Pythium spp. Mol. PlantMicrobe Interact. 11:847-854.

Becker, J. O., and Cook, R. J. 1988. Role of siderophores in suppression of Pythium species and production of increased-growth response of wheat by fluorescent pseudomonads. Phytopathology 78:778-782.

Boyer, H. W., and Roulland-Dussoix, D. 1969. A complementation analysis of the restriction and modification of DNA in Escherichia coli. J. Mol. Biol. 41:459-472.

Chatterjee, A., Cui, Y., Liu, Y., Dumenyo, C. K., and Chatterjee, A. K. 1995. Inactivation of $r \operatorname{smA}$ leads to overproduction of extracellular pectinases, cellulases, and proteases in Erwinia carotovora subsp. carotovora in the absence of the starvation/cell density-sensing signal, $\mathrm{N}$-(3-oxohexanoyl)-L-homoserine lactone. Appl. Environ. Microbiol. 61:1959-1967.

Chin-A-Woeng, T. F. C., Bloemberg, G. V., Van der Bij, A. J., Van der Drift, K. M. G. M., Schripsema, J., Kroon, B., Scheffer, R. J., Keel, C., Bakker, P. A. H. M., Tichy, H.-V., De Bruijn, F. J., Thomas-Oates, J. E., and Lugtenberg, B. J. J. 1998. Biocontrol by phenazine-1carboxamide-producing Pseudomonas chlororaphis PCL1391 of tomato root rot caused by Fusarium oxysporum f. sp. radicislycopersici. Mol. Plant-Microbe Interact. 11:1069-1077.

Cook, R. J., Thomashow, L. S., Weller, D. M., Fujimoto, D., Mazzola, M., Bangera, G., and Kim, D. 1995. Molecular mechanisms of defense by rhizobacteria against root disease. Proc. Natl. Acad. Sci. USA 92:4197-4201.

De Boer, M., Van, D. S. I., Van-Loon, L. C., and Bakker, P. A. H. M. 1999. Combining fluorescent Pseudomonas spp. strains to enhance suppression of Fusarium wilt of radish. Eur. J. Plant Pathol. 105:201210.

Delaney, S. M., Mavrodi, D. V., Bonsall, R. F., and Thomashow, L. S. 2001. phzO, a gene for biosynthesis of 2-hydroxylated phenazine 
compounds in Pseudomonas aureofaciens 30-84. J. Bacteriol. 183:318-327.

Di Pietro, A., Lorito, M., Hayes, C. K., Broadway, R. M., and Harman, G. E. 1993. Endochitinase from Gliocladium virens: Isolation, characterisation, and synergistic antifungal activity in combination with gliotoxin. Phytopathology 83:308-312.

Duffy, B. K., Simon, A., and Weller, D. M. 1996. Combination of Trichoderma koningii with fluorescent pseudomonads for control of take-all on wheat. Phytopathology 86:188-194.

Dunlap, C., Crowley, J. J., Moënne-Loccoz, Y., Dowling, D. N., De Bruijn, F. J., and O'Gara, F. 1997. Biological control of Pythium ultimum by Stenotrophomonas maltophilia W81 is mediated by an extracellular proteolytic activity. Microbiology 143:3921-3931.

Dunne, C., Moënne-Loccoz, Y., McCarthy, J., Higgins, P., Powell, J., Dowling, D., and O'Gara, F. 1998. Combining proteolytic and phloroglucinol-producing bacteria for improved biocontrol of $P y$ thium-mediated damping-off of sugar beet. Plant Pathol. 47:299-307.

Fernandez, R. O., and Pizarro, R. A. 1997. High-performance liquid chromatographic analysis of Pseudomonas aeruginosa phenazines. J. Chromatogr. A 771:99-104.

Geels, F. P., and Schippers, G. 1983. Selection of antagonistic fluorescent Pseudomonas spp. and their root colonization and persistence following treatment of seed potatoes. Phytopathol. Z. 108:193-206.

Gerber, N. N. 1984. Microbial phenazines. Pages 573-576 in: CRC Handbook of Microbiology. A. I. Laskin and H. A. Lechevalier, eds. Chemical Rubber, Cleveland.

Gilbert, W., and Maxam, A. 1973. The nucleotide sequence of the lac operator. Proc. Natl. Acad. Sci. USA 70:3581-3584.

Heeb, S., Itoh, Y., Nishijyo, T., Schnider, U., Keel, C., Wade, J., Walsh, U., O'Gara, F., and Haas, D. 2000. Small, stable shuttle vectors based on the minimal pVS1 replicon for use in gram-negative, plantassociated bacteria. Mol. Plant Microbe Interact. 13:232-237.

Howell, C. R., and Stipanovic, R. D. 1979. Control of Rhizoctonia solani on cotton seedlings with Pseudomonas fluorescens and with an antibiotic produced by the bacterium. Phytopathology 69:480-482.

Ingram, J. M., and Blackwood, A. C. 1970. Microbial production of phenazines. Adv. Microb. Physiol. 13:267.

Jijakli, M. H., and Lepoivre, P. 1998. Characterization of an exo- $\beta-1,3-$ glucanase produced by Pichia anomala strain K, antagonist of Botrytis cinerea on apples. Phytopathology 88:335-343.

Keel, C., Schnider, U., Maurhofer, M., Voisard, C., Laville, J., Burger, U., Wirthner, P., Haas, D., and Défago, G. 1992. Suppression of root diseases by Pseudomonas fluorescens CHA0: Importance of the bacterial secondary metabolite 2,4-diacetylphloroglucinol. Mol. PlantMicrobe Interact. 5:4-13.

King, E. O., Ward, M. K., and Raney, D. E. 1954. Two simple media for the demonstration of pyocyanin and fluorescein. J. Lab. Clin. Med. 44:301-307.

Lorito, M., Peterbauer, C., Hayes, C. K., and Harman, G. E. 1994. Synergistic interaction between fungal cell wall degrading enzymes and different antifungal compounds enhances inhibition of spore germination. Microbiology 140:623-629.

Lugtenberg, B. J. J., Kravchenko, L. V., and Simons, M. 1999. Tomato seed and root exudate sugars: Composition, utilization by Pseudomonas biocontrol strains and role in rhizosphere colonization. Environ. Microbiol. 1:439-446.

Marsh, J. L., Erfle, M., and Wykes, E. J. 1984. The pIC20 plasmid and phage vectors with versatile cloning sites for recombinant selection by insertional inactivation. Gene 32:481-485.

Massiere, F., and Badet, D. M. 1998. The mechanism of glutaminedependent amidotransferases. Cell Mol. Life Sci. 54:205-222.
Mavrodi, D. V., Ksenzenko, V. N., Bonsall, R. F., Cook, R. J., Boronin, A. M., and Thomashow, L. S. 1998. A seven-gene locus for synthesis of phenazine-1-carboxylic acid by Pseudomonas fluorescens 2-79. J. Bacteriol. 180:2541-2548.

O'Sullivan, M., Stephens, P. M., and O'Gara, F. 1991. Extracellular protease production by fluorescent Pseudomonas spp. and the colonization of sugarbeet roots and soil. Soil Biol. Biochem. 23:623627.

Pierson, L. S., Gaffney, T., Lam, S., and Gong, F. 1995. Molecular analysis of genes encoding phenazine biosynthesis in the biological control bacterium Pseudomonas aureofaciens 30-84. FEMS Microbiol. Lett. 134:299-307.

RuizDuenas, F. J., and Martinez, M. J. 1996. Enzymatic activities of Trametes versicolar and Pleurotus eryngii implicated in biocontrol of Fusarium oxysporum f. sp. lycopersici. Curr. Microbiol. 32:151-155.

Sambrook, J., Fritsch, E. F., and Maniatis, T. 1989. Molecular Cloning: A Laboratory Manual. Cold Spring Harbor Laboratory, Cold Spring Harbor, NY, U.S.A.

Sands, D. C., and Rovira, A. D. 1971. Pseudomonas fluorescens biotype $\mathrm{G}$, the dominant fluorescent pseudomonad in South Australian soils and wheat rhizospheres. J. Appl. Bacteriol. 34:261-275.

Shapira, R., Ordentlich, A., Chet, I., and Oppenheim, A. B. 1989. Control of plant diseases by chitinase expressed from cloned DNA in Escherichia coli. Phytopathology 79:1246-1249.

Stover, C. K., Pham, X. Q., Erwin, A. L., Mizoguchi, S. D., Warrener, P., Hickey, M. J., Brinkman, F. S., Hufnagle, W. O., Kowalik, D. J., Lagrou, M., Garber, R. L., Goltry, L., Tolentino, E., WestbrockWadman, S., Yuan, Y., Brody, L. L., Coulter, S. N., Folger, K. R., Kas, A., Larbig, K., Lim, R., Smith, K., Spencer, D., Wong, G. K., Wu, Z., and Paulsen, I. T. 2000. Complete genome sequence of Pseudomonas aeruginosa PA01, an opportunistic pathogen. Nature 406:959-964.

Thomashow, L. S., and Weller, D. M. 1988. Role of a phenazine antibiotic from Pseudomonas fluorescens in biological control of Gaeumannomyces graminis var. tritici. J. Bacteriol. 170:3499-3508.

Thomashow, L. S., Weller, D. M., Bonsall, R. F., and Pierson, L. S., III 1990. Production of the antibiotic phenazine-1-carboxylic acid by fluorescent Pseudomonas species in the rhizosphere of wheat. Appl. Environ. Microbiol. 56:908-912.

Timms-Wilson, T. M., Ellis, R. J., Renwick, A., Rhodes, D. J., Mavrodi, D. V., Weller, D. M., Thomashow, L. S., and Bailey, M. J. 2000. Chromosomal insertion of phenazine-1-carboxylic acid biosynthetic pathway enhances efficacy of damping-off disease control by Pseudomonas fluorescens. Mol. Plant Microbe Interact. 13:1293-1300.

Toohey, J. I., Nelson, C. D., and Krotkov, G. 1965. Toxicity of phenazine carboxylic acid to some bacteria, algae, higher plants, and animals. Can. J. Bot. 43:1151-1155.

Turner, J. M., and Messenger, A. J. 1986. Occurrence, biochemistry and physiology of phenazine pigment production. Adv. Microb. Physiol. 27:211-275.

Van der Bij, A. J., De Weger, L. A., Tucker, W. T., and Lugtenberg, B. J. J. 1996. Plasmid stability in Pseudomonas fluorescens in the rhizosphere. Appl. Environ. Microbiol. 62:1076-1080.

Voisard, C., Keel, C., Haas, D., and Defago, G. 1989. Cyanide production by Pseudomonas fluorescens helps suppress black root rot of tobacco under gnotobiotic conditions. EMBO J. 8:351-358.

Weller, D. M., and Cook, R. J. 1983. Suppression of take-all of wheat by seed treatments with fluorescent pseudomonads. Phytopathology 73:463-469.

Wolk, C. P., Cai, Y., and Panoff, J. M. 1991. Use of a transposon with luciferase as a reporter to identify environmentally responsive genes in a cyanobacterium. Proc. Natl. Acad. Sci. USA 88:5355-5359. 